\title{
STUDY OF OXIDE LAYERS IN CREEP OF Ti ALLOY
}

\author{
Reis, D.A.P. ${ }^{1, a}$; Machado, J.P.B. ${ }^{2, b}$; Martins, G.V. ${ }^{2, c}$; Moura Neto, C. ${ }^{1, d}$; Barboza, M.J.R. ${ }^{3, e}$; \\ ${ }^{1}$ Instituto Tecnológico de Aeronáutica, ITA, São José dos Campos, Brazil. \\ 2 Instituto Nacional de Pesquisas Espaciais, São José dos Campos, Brazil. \\ ${ }^{3}$ Escola de Engenharia de Lorena, EEL-USP, Lorena, Brazil. \\ ${ }^{4}$ Instituto de Pesquisas Energéticas e Nucleares, IPEN, São José dos Campos, Brazil \\ ${ }^{5}$ Universidade Presbiteriana Mackenzie, São Paulo, Brasil. \\ adanielireis@hotmail, bjoaopaulo@las.inpe.br, 'givmartins@yahoo.com.br, ${ }^{\mathrm{d}}$ mneto@ita.br, \\ emibarboza@uol.com, 'acouto@ipen.br
}

Keywords: titanium alloy, oxidation, high temperature, creep.

\begin{abstract}
The present study is about the effect of oxide layers in creep of Ti-6Al-4V alloy, in different atmospheres (air, nitrogen and argon). Ti-6Al-4V alloy was treated during 24 hours in a thermal treatment furnace at $600^{\circ} \mathrm{C}$ in different atmospheres (argon, nitrogen and air). The samples were analyzed by High Resolution X-Ray Diffraction, Scanning Electronic Microscopy (SEM), Atomic Force Microscopy (AFM) and microhardness test. The polished samples of Ti-6Al-4V allloy were treated during 24 hours at $600^{\circ} \mathrm{C}$ and the oxidation behavior in each case using argon, nitrogen and air atmospheres was observed. The oxidation was more aggressive in air atmosphere, forming $\mathrm{TiO}_{2}$ film in the surface. The oxidation produced a weight gain through the oxide layer growth and hardening by oxygen dissolution. Ti-6Al-4V alloy specimens also were produced in order to test them in creep, at $250 \mathrm{MPa}$ and $600^{\circ} \mathrm{C}$, with argon, nitrogen and air atmospheres. When the Ti-6Al-4V alloy was tested under argon and nitrogen atmospheres oxidation effects are smaller and the behavior of the creep curves shows that the creep life time was better in atmospheres not so oxidant. It is observed a decreasing of steady state creep in function of the oxidation process reduction. It is shown that, for the Ti-6Al-4V alloy, their useful life is strongly affected by the atmosphere that is submitted, on account of the oxidation suffered by the material.
\end{abstract}

\section{INTRODUCTION}

One of the major factors limiting the life of titanium alloys in service is their degradation due to gaseous environments, in particular, the one containing oxygen, especially at elevated temperatures, during the long term use [1]. The sensitivity of titanium alloys to high temperature exposure is a well-known phenomenon. When titanium alloys are heated to temperatures above approximately $800^{\circ} \mathrm{C}$, oxygen, hydrogen and nitrogen penetrate into them. The penetration of the above elements is thought to be undesirable because it increases hardness and brittleness while decreasing the toughness of the alloy [2]. Interaction of titanium alloys with oxygen not only causes loss of the material by formation of oxides, but also causes embrittlement in the subsurface zone of the component due to oxygen enrichment [1].

Titanium naturally resists corrosion from acids, alkalis, and natural, salt and polluted waters. In fact, titanium's resistance to seawater is equivalent to that of platinum. This is because titanium is a reactive metal, spontaneously forming a hard, protective oxide film when it comes in contact with any oxygen - as in air or water. If the film is scratched or damaged, as long as oxygen is present it will heal itself. The protective film also makes titanium very resistant to erosion. In high velocity process streams and in rapidly flowing seawater, it can be at least twenty times more erosion resistant than copper-nickel alloys. Titanium's naturally occurring oxide film also gives the 
metal its unique, softly shimmering beauty. When the thickness of the film is increased (through anodic oxidation) it changes the appearance of the metal over a spectrum of colors [3-5].

The chemical reactivity of titanium is dependent upon temperature. The metal's action with other substances proceeds more readily at elevated temperatures. This property is specially exemplified by the metal's extreme reactivity to the gases of the atmosphere at high temperatures. This necessitates the use of inert atmospheres for hot working and surface protection for high temperature applications. The rapid combination of titanium with the reactive gases of the atmosphere above $510^{\circ} \mathrm{C}$ produces surface scale. With larger intervals of time and increase in temperature, the gases diffuse into the lattice. The metal combines with oxygen to form a long series of oxides from $\mathrm{TiO}$ to $\mathrm{Ti}_{7} \mathrm{O}_{12}$, each of which exhibits a different hue and at short time exposures, a rainbow-colored surface film is produced. Although this surface oxidation proceeds at $510^{\circ} \mathrm{C}$, no appreciable diffusion into the lattice occurs below $704^{\circ} \mathrm{C}$. Ignition of the metal occurs in air at $1204^{\circ} \mathrm{C}$, and a pure oxygen atmosphere reduces this temperature to $610^{\circ} \mathrm{C}$. Its burning is accompanied by a very bright incandescence, a state which is also produced in a nitrogen atmosphere at temperatures above $816^{\circ} \mathrm{C}$ [6-9].

The reactivity of titanium with nitrogen is similar to its action with oxygen where a yellowbrown scale is formed on the surface as the nitride [4]. Titanium nitride has attracted interest due to its characteristic high hardness and gold-yellow color, and is widely applied as a surface coating [5]. Nitrogen will diffuse into the lattice with a restricted depth of penetration. This property has been employed in the nitride casing of the metal. Most unique of the gas-titanium reactions is that between hydrogen and the metal. The reaction proceeds at temperatures slightly above room temperature, and as much as $400 \mathrm{~cm}^{3}$ of the gas can be absorbed by one gram of titanium. In small amounts the gas adds as an interstitial, but at higher concentrations the hydride $\mathrm{TiH}$ is formed. The addition of hydrogen to titanium is only stable, however, below $360^{\circ} \mathrm{C}$; above this temperature the gas is evolved and burns. Early work employed this action to form a protective atmosphere around the metal during some hot processes. The burning hydrogen being evolved penetration by any other gas. However, since the gas is not recoverable, the cost is prohibitive [4]. It has long been known that oxygen, like nitrogen and carbon, can significantly harden titanium alloys, however, little work on the oxidation of titanium alloys has been undertaken from a surface engineering viewpoint [1013].

The aim of the present paper was to study the oxidation effect in creep of the Ti-6Al-4V alloy, in different atmospheres of test (air, nitrogen and argon). A substantial part of the creep research has been devoted to Ti-6Al-4V due to its industrial and technological importance. Its creep properties in air have been well documented. However, its creep behavior in nitrogen and argon atmospheres has only rarely been investigated.

\section{EXPERIMENTAL}

The Ti-6Al-4V alloy was in the form of ingot with length of $1 \mathrm{~m}$ and $1.27 \mathrm{~cm}$ of diameter, acquired from Multialloy Eng. Mat. Ltda, forged and annealed at $190^{\circ} \mathrm{C}$ during 6 hours and air cooled. The Ti-6Al-4V alloy was cutted in form of disk with length of $0.5 \mathrm{~cm}$ and $1.27 \mathrm{~cm}$ of diameter. The characterization of the chemical composition of main elements (wt \%), was adequate of the ASTM regulation (B265-89) [5], using the Inductively Coupled Plasma Optical Emission Spectroscopy (ICP-OES) in an ARL equipment 3410 model [6].

The samples of Ti-6Al-4V were polished and treated during 24 hours in a thermal treatment furnace at $600^{\circ} \mathrm{C}$ in different atmospheres (argon, nitrogen and air). The samples were analyzed by High Resolution X-Ray Diffraction (difratometer X'Pert - MRD Philips with a PW 3050 goniometer), Scanning Electron Microscopy (microscopy LEO 435 VPI model microscope), Atomic Force Microscopy - AFM (Shimadzu SPM-9500J3 microscope), Surface Profiler (Tencor) and microhardness test (Digital Microhardness Tester Future Tech FM model). It has to be noted 
that, prior to the AFM analysis, all the samples were cleaned with acetone in an ultrasonic bath for $15 \mathrm{~min}$.

Using the Ti-6Al-4V alloy produced specimens to creep test; the specimens were tested in creep at $600^{\circ} \mathrm{C}$ in argon, nitrogen and air atmospheres using $250 \mathrm{MPa}$. Creep tests were realized using MAYES machines from Instituto Tecnológico de Aeronáutica - ITA. In the furnace were adapted electrical systems and controllers according to ASTM E139/83 standardization [14]. Antares Software was used to collect the data on the elongation of the samples and the measuring of temperature in pre determined periods of time. It was used a transducer-type LVDT Schlumberger D 6.50 to obtain measures of elongation and it was used Cromel-Alumel thermocouple type AWG24 to control temperature.

\section{RESULTS}

The results obtained by ICP-OES were of $89.16 \mathrm{wt} \%$ of Ti, $6.61 \mathrm{wt} \%$ of $\mathrm{Al}$ and $4.23 \mathrm{wt} \%$ of V. The Figure 1 presents the High Resolution X-Ray Diffraction for a sample without treatment and treated in different atmospheres (air, nitrogen and argon). The results show that only for the sample treated in air atmosphere presented the $\mathrm{TiO}_{2}$ film in the surface. It was because the oxidation was more aggressive in air atmosphere, forming $\mathrm{TiO}_{2}$ film in the sample surface and the sample color was dark gray. In argon and nitrogen atmospheres the oxidation suffered by material was not detected by High Resolution X-Ray Diffraction, just color change was observed (blue in argon and yellow in nitrogen).

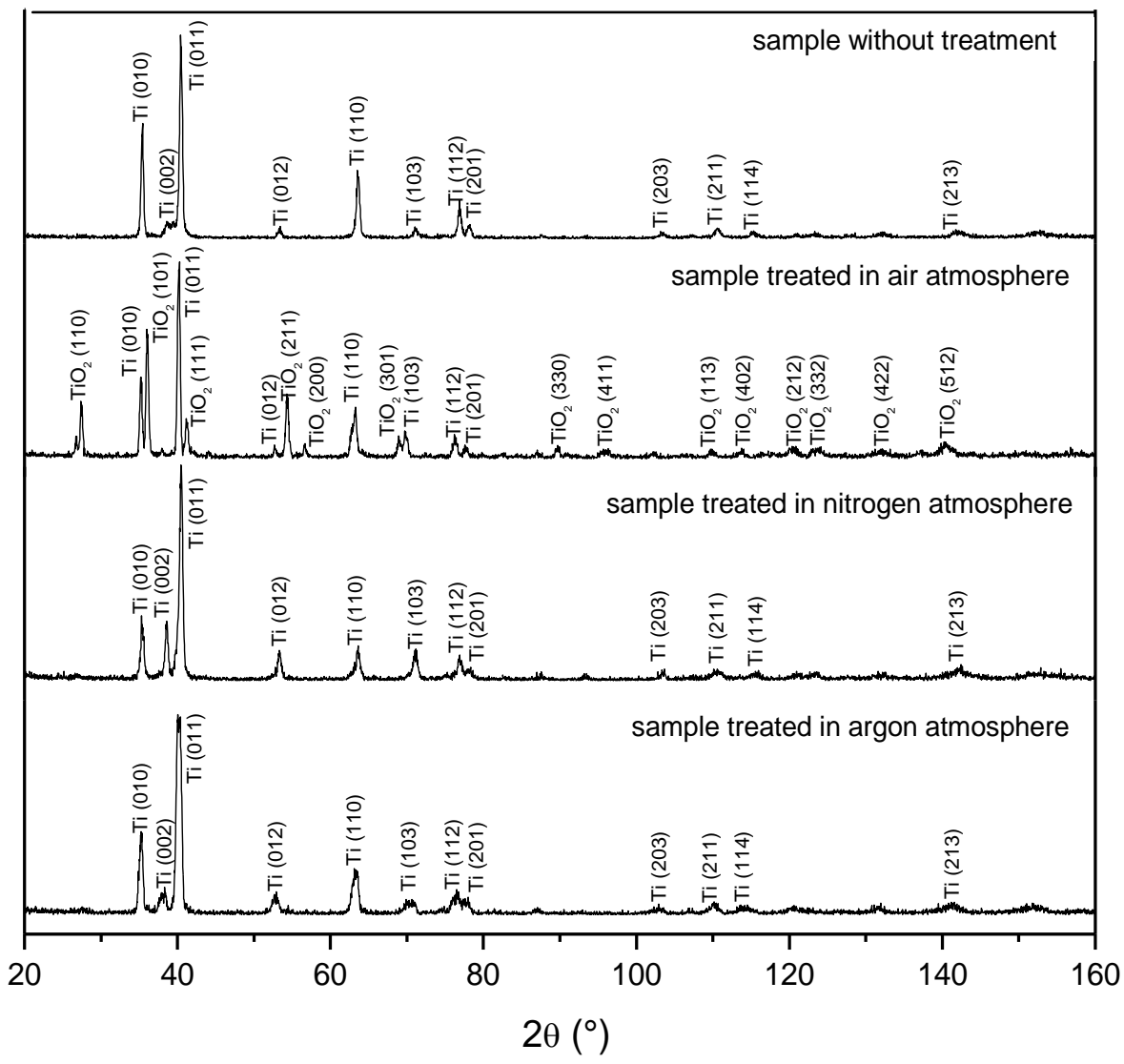

Figure 1. High Resolution X-Ray Diffraction of the Ti-6Al-4V samples treated in different conditions of atmosphere 
The oxidation layer, presents at sample treated in air, was approximately $0.81 \mu \mathrm{m}$ and its surface roughness was approximately $50 \mathrm{~nm}$ in the case of highest oxidation when formed $\mathrm{TiO}_{2}$ film (Figure 2).

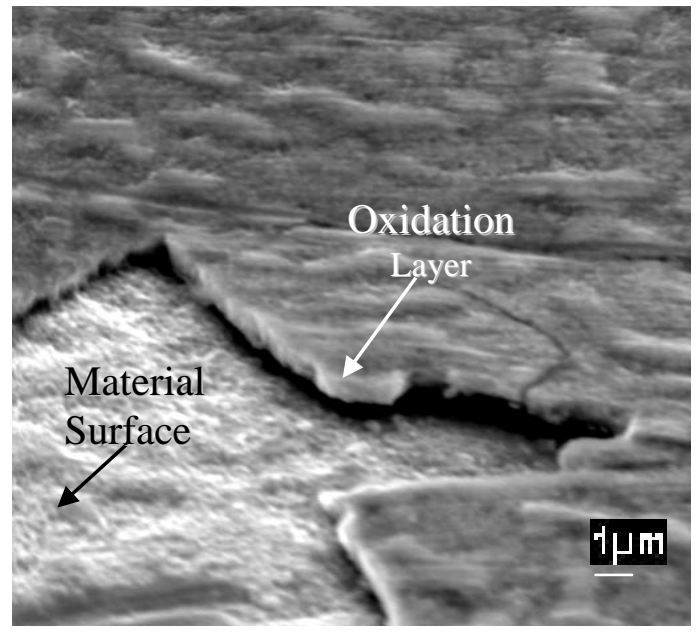

Figure 2. Microstructure of oxidation layer by SEM from as sample treated in air atmosphere.

Figure 3 presents the surfaces obtained by AFM for Ti-6Al-4V samples: without treatment (a), treated in air atmosphere (b), treated in nitrogen atmosphere (c) and treated in argon atmosphere (d). The surface of all samples presented a dome-shaped morphology, but one can observe that samples without treatment and treated in argon atmosphere have higher spatial frequencies compared to samples treated in air and nitrogen atmospheres [15].

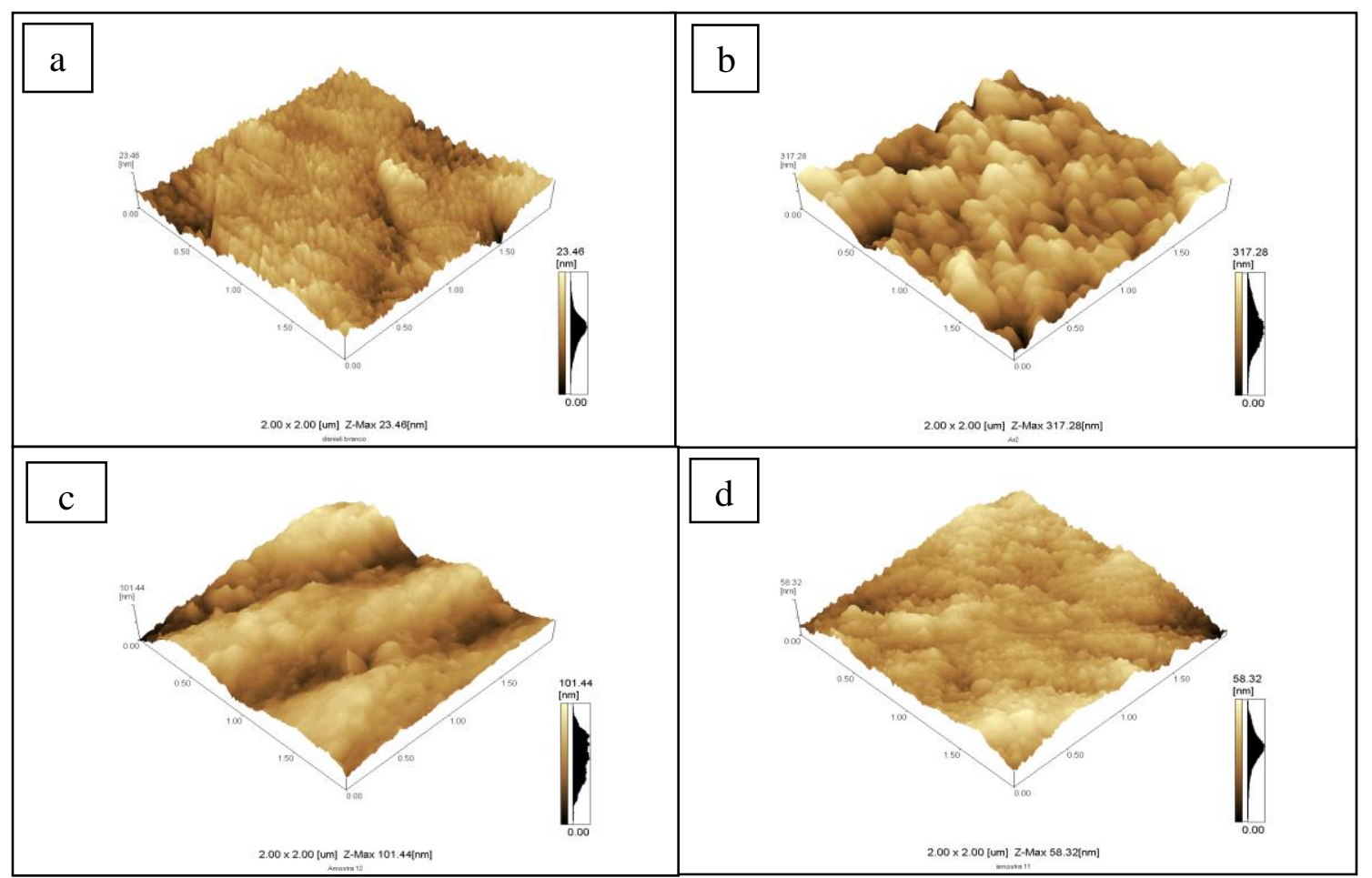

Figure 3. Surface morphology obtained by AFM: a) sample without treatment, b) sample treated in air atmosphere, c) sample treated in nitrogen atmosphere and d) sample treated in argon atmosphere. 
The surface roughness and microhardness values are presented in Table 1. The samples microhardness values showing that the oxidation leads to the microhardness increasing, the values of roughness are in agreement of the microhardness.

Table 1. Microhardness and roughness measures of the Ti-6Al-V samples treated in different conditions of atmosphere.

\begin{tabular}{|c|c|c|}
\hline Sample & Microhardness $(\mathrm{HV})$ & Roughness $(\mathrm{nm})$ \\
\hline without treatment & 336 & 2.877 \\
\hline air atmosphere & 781 & 50.861 \\
\hline nitrogen atmosphere & 495 & 17.564 \\
\hline argon atmosphere & 393 & 8.078 \\
\hline
\end{tabular}

The Figure 4 shows the creep curves obtained at $600^{\circ} \mathrm{C}$ in argon, nitrogen and air atmospheres using $250 \mathrm{MPa}$.

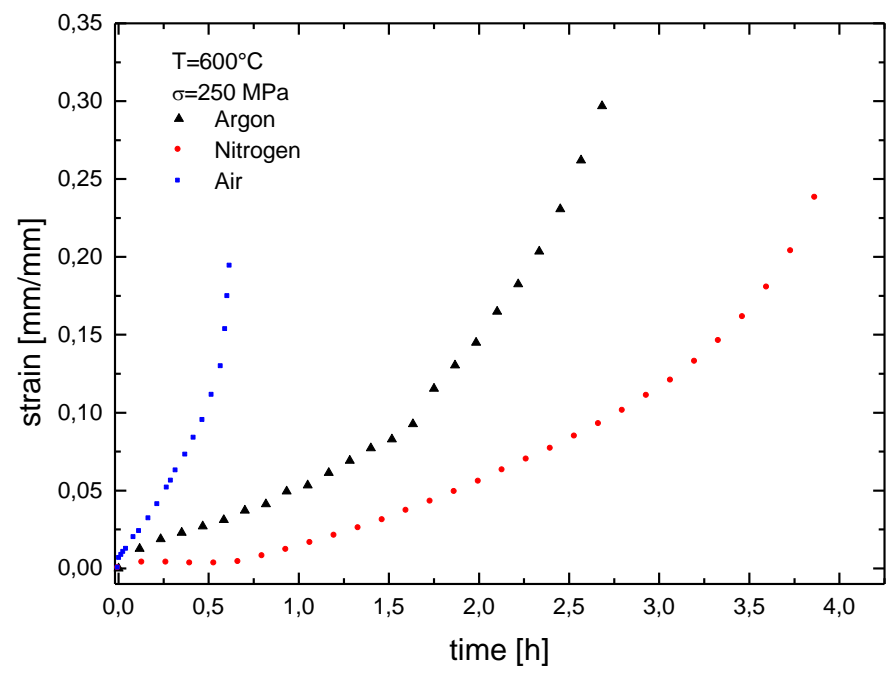

Figure 4. Creep curves at $600^{\circ} \mathrm{C}$ and $250 \mathrm{MPa}$ obtained in argon, nitrogen and air atmospheres.

Results from the creep tests are summarized in Table 2, which shows the values of stress $(\sigma)$, primary creep time $\left(t_{p}\right)$, secondary creep rate $\left(\varepsilon_{s}\right)$, final creep time $\left(t_{f}\right)$, final strain $\left(\varepsilon_{f}\right)$ and reduction of area (RA).

Table 2. Creep data of Argon, Nitrogen and Air atmosphere at $600^{\circ} \mathrm{C}$ and $250 \mathrm{MPa}$.

\begin{tabular}{|c|c|c|c|c|c|}
\hline Atmosphere & $\begin{array}{c}\mathbf{t}_{\mathbf{p}} \\
(\mathbf{h})\end{array}$ & $\begin{array}{c}\dot{\boldsymbol{\varepsilon}_{\mathbf{s}}} \\
(\mathbf{1} / \mathbf{h})\end{array}$ & $\begin{array}{c}\mathbf{t}_{\mathbf{f}} \\
(\mathbf{h})\end{array}$ & $\begin{array}{c}\boldsymbol{\varepsilon}_{\mathbf{f}} \\
(\mathbf{m m} / \mathbf{m m})\end{array}$ & $\begin{array}{c}\mathbf{A R} \\
(\mathbf{\%})\end{array}$ \\
\hline Argon & 0.12 & 0.0526 & 2.91 & 0.408 & 57.32 \\
\hline Nitrogen & 0.35 & 0.0317 & 3.68 & 0.341 & 65.97 \\
\hline Air & 0.03 & 0.1597 & 0.62 & 0.194 & 75.83 \\
\hline
\end{tabular}

When the Ti-6Al-4V was treated in argon and nitrogen atmospheres the effect the oxidation is smaller and the behavior of the creep curves shows that the lifetime is larger in atmospheres not so oxidant. There is an increasing of ductility of material (final deformation). Occurs a decreasing of steady state creep in function of the reduction of oxidation process, showing that for the Ti-6Al-4V alloy their lifetime is strongly affected by the atmosphere that is submitted because the oxidation suffered by the material. The fact of the nitrogen atmosphere got higher creep resistance can be correlated to the hard and thin nitride surface layer formed during creep tests offer to the 
Ti-6Al-4V alloy [2]. It is a well-known fact that hard surface layers and interstitial solid solutions increase the creep resistance of certain alloys. The thin nitride layer formed during creep tests increases rupture life. It is possible that controlled penetration of oxygen into the alloy Ti-6Al-4V could increase its creep resistance without seriously altering its ductility [2]. However, the steadystate creep rate demonstrates that the higher creep resistance of Ti-6Al-4V is observed on samples in nitrogen and argon atmospheres.

\section{CONCLUSIONS}

When the Ti-6Al-4V was treated in argon and nitrogen atmospheres the effect the oxidation is smaller and the creep behavior is better in atmospheres not so oxidant. The oxidation was more aggressive in air atmosphere, forming $\mathrm{TiO}_{2}$ film in the surface. The oxidation produced a weight gain through the oxide layer growth and hardening by oxygen dissolution. The fact of the nitrogen atmosphere got higher creep resistance can be correlated to the hard and thin nitride surface layer formed during creep tests. The steady-state creep rate demonstrates that the higher creep resistance of Ti-6Al-4V is observed on samples in nitrogen and argon atmospheres.

\section{ACKNOWLEDGMENTS}

CNPq, CAPES and FAPESP for financial support.

\section{REFERENCES}

[1] Sai Srinadh, K.V. and Singh, V. Bull. Mater. Sci. 27 (2004), p.347-354.

[2] Rosen, A. and Rottem, A. Mater. Sci. Eng. 22 (1976), p.23-29.

[3] Abkowitz, S., Burke, J.J. and Hiltz Jr., R. H. Technology of Structural Titanium. D. Van Nostrand Company, (1955), pp.31-32.

[4] Huang, C. T. and Duh, J.G., Vacuum, 46 (1995), 1465 p.

[5] Dong, H. and Li, X.Y. Materials Science and Engineering A, 280, (2000), p.304.

[6] American Society for Testing and Materials, (1990), Philadelphia, B265-89, p.6.

[7] Reis, D.A.P.; Silva, C.R.M.; Nono, M.C.A.; Barboza, M.J.R..; Piorino, F.; Perez, E.A.C. Materials Science and Engineering A, 399 (2005), p.276-280.

[8] Barboza, M.J.R.; Moura Neto, C.; Silva, C.R.M. Materials Science and Engineering A, 369 (2004), p. 201-209.

[9] Reis, D.A.P.; Silva, C.R.M.; Nono, M.C.A.; Barboza, M.J.R..; Piorino, F. SAE Technical Papers Series, 01-2866 (2006), p.1-4.

[10] Reis, D.A.P.; Silva, C.R.M.; Nono, M.C.A.; Barboza, M.J.R..; Piorino, F.; Vieira, R.A. Materials Science Forum, 530-531 (2006), p.690-695.

[11] Reis, D.A.P.; Silva, C.R.M.; Nono, M.C.A.; Barboza, M.J.R..; Piorino, F.; Perez, E.A.C. Materials at High Temperatures, 22 (2006), p.449-452.

[12] Reis, D.A.P.; Silva, C.R.M.; Nono, M.C.A.; Barboza, M.J.R..; Piorino, F.; Vieira, R.A. Brazilian Journal of Morphological Sciences, Supplement A (2005), p.367-368.

[13] Reis, D.A.P.; Silva, C.R.M.; Nono, M.C.A.; Barboza, M.J.R..; Piorino, F. Acta Microscopica, 12, Supplement C (2003), p.219-220, 2003. http://sbmm.org.br/acta

[14] American Society for Testing and Materials, (1990) Surface Engineering,5, Philadelphia.

[15] R.V. Bathomarco, G. Solorzano, C.N. Elias, R. Prioli. Applied Surface Science 233 (2004), p.29-34. 